\title{
Altered expression of DNA-dependent protein kinase catalytic subunit (DNA-PKcs) during gastric carcinogenesis and its clinical implications on gastric cancer
}

\author{
HYE SEUNG LEE ${ }^{1}$, GHEEYOUNG CHOE ${ }^{2}$, KYOUNG UN PARK ${ }^{3}$, DO JOONG PARK ${ }^{4}$, \\ HAN-KWANG YANG ${ }^{4,5}$, BYUNG LAN LEE ${ }^{5}$ and WOO HO KIM ${ }^{2,5}$
}

\begin{abstract}
${ }^{1}$ Department of Pathology, Seoul National University Bundang Hospital, 300 Gumi-dong, Bundang-gu, Seongnam, Gyeonggi 463-707; Departments of ${ }^{2}$ Pathology,${ }^{3}$ Laboratory Medicine, ${ }^{4}$ Surgery and ${ }^{5}$ Cancer Research Institute, Seoul National University College of Medicine, 28 Yongon-dong, Chongno-gu, Seoul 110-799, Korea
\end{abstract}

Received May 3, 2007; Accepted June 29, 2007

\begin{abstract}
DNA-dependent protein kinase catalytic subunit (DNA-PKcs) is a $465-\mathrm{kDa}$ catalytic subunit of DNA-PK, a DNA repair apparatus. DNA-PKcs has been reported to be a tumor suppressor, but details of its expression in human cancer are controversial. To determine the protein expression and clinical implications of DNA-PKcs in gastric carcinogenesis and cancer progression, we evaluated its expression status by immunohistochemistry in 122 non-neoplastic gastric mucosa samples, and in 115 gastric adenomas and 564 consecutive gastric cancers. In addition, we evaluated the clinicopathologic characteristics of gastric cancers showing altered DNA-PKcs expression, and performed microsatellite instability (MSI) analysis at BAT-26 and frameshift mutation analysis of DNA-PKcs. DNA-PKcs expression was negative in foveolar epithelium of normal gastric mucosal tissues, but was positive in most Helicobacter pylori-associated gastritis, intestinal metaplasia and gastric adenoma tissues. In gastric cancers, negative expression of DNA-PKcs was found in 114 of the $564(20.2 \%)$ cancers and was significantly associated with intratumoral neutrophils, MSI-high $(\mathrm{H})$ phenotype, tumor progression, and poor patient survival $(\mathrm{p}<0.05)$. Frameshift mutations of $(\mathrm{A})_{10}$ mononucleotide repeats in DNA-PKCs were found in $24.3 \%$ of MSI-H gastric cancers
\end{abstract}

Correspondence to: Dr Woo Ho Kim, Department of Pathology, Seoul National University College of Medicine, 28 Yongon-dong, Chongno-gu, Seoul 110-799, Korea

E-mail:woohokim@snu.ac.kr

Abbreviations: DNA-PKcs, DNA-dependent protein kinase catalytic subunit; DSBs, DNA double-strand breaks; MSI, microsatellite instability; MSI-H, microsatellite instability-high; MSS, microsatellite stable; HNPCC, hereditary non-polyposis colon cancer; HE, hematoxylin and eosin

Key words: stomach neoplasms, immunohistochemistry, PRKDC protein, survival analysis, microsatellite instability, frameshift mutation and these were associated with negative expression of DNAPKcs. Although patients with MSI-H gastric cancers were found to have a lower risk of lymph node metastasis, gastric cancers harboring the $(\mathrm{A})_{10}$ mutation of DNA-PKcs were found to have a higher risk of lymph node metastasis. In conclusion, the expression of DNA-PKcs was found to be altered during gastric carcinogenesis and negative DNA-PKcs expression was associated with gastric cancer progression. The (A) $)_{10}$ frameshift mutation of DNA-PKcs in gastric cancers was a target of defective mismatch repair, and was associated with lymph node metastasis.

\section{Introduction}

DNA-dependent protein kinase (DNA-PK, PRKDC) is a serine/threonine kinase that consists of a $465-\mathrm{kDa}$ catalytic subunit (DNA-PKcs) and the heterodimeric regulatory complex $\mathrm{Ku}$, which is composed of a $70-\mathrm{kDa}(\mathrm{Ku} 70)$ and an $86-\mathrm{kDa}$ (Ku86) polypeptide. DNA-PK is a critical regulator of the repair of DNA double-strand breaks (DSBs) induced by ionizing radiation (1). It is generally believed that $\mathrm{Ku}$ helps recruit DNA-PKcs to DNA and that it is required for the physiological activation of DNA-PK at sites of DNA damage $(2,3)$. Lack of DNA-PK is associated with defective DNA DSB repair and radiosensitization, and DNA-PKcs has been identified as a therapeutic candidate. Daido et al reported that the specific inhibition of DNA-PKcs radiosensitized malignant glioma cells (4). Moreover, DNA-PK expression has been upregulated after radiation treatment, and this upregulation was found to be correlated with tumor radiation resistance in oral squamous cell carcinoma, thus suggesting that DNA-PKcs might be a molecular target for radiation sensitization therapy in oral squamous cell carcinoma (5).

In gastrointestinal cancers, a recent study found that hyperplasia and dysplasia of intestinal mucosa and production of aberrant crypt foci developed in DNA-PKcs-null mice, but not in Ku70-/- and Ku86-/- mice (6), which suggests that DNA-PKcs may play an important role as a tumor suppressor, at least in intestinal mucosa. In contrast, Rigas et al reported that DNA-PKcs expression was not significantly altered in colon cancers compared to normal controls (7), and 
Hosoi et al found that DNA-PK activity and the protein- and mRNA-levels of Ku70, Ku80 and DNA-PKcs were elevated in the tumor tissues of colorectal cancer patients linked with $\mathrm{Sp} 1$ protein upregulation in tumor tissues (8). Despite its roles in DNA repair pathways and radiosensitization, the expression and functional status of DNA-PKcs are uncertain in gastrointestinal cancers.

Microsatellite instability (MSI) is a form of genomic instability that is associated with defective DNA mismatch repair in tumors (9). The majority of hereditary non-polyposis colon cancer (HNPCC) syndrome cancers (10) and about $10-15 \%$ of unselected gastric and colorectal cancers have MSI-high $(\mathrm{H})$ phenotype $(11,12)$. MSI-H cancers have frequent mutations of genes with repeat sequences in their coding regions, e.g., TGFßRII, BAX, hMSH3, and E2F4 (12). The DNA-PKCS gene has two mononucleotide repeats $\left[\operatorname{poly}(\mathrm{A})_{8}\right.$ and poly $(\mathrm{A})_{10}$ tracts], and could be a target of defective DNA mismatch repair. Recently, (A) $)_{10}$ mutation of DNA-PKcs was reported in MSI-H urothelial, colorectal, and gastric cancers $(13,14)$. However, relationships between frameshift mutation of DNA-PKCs and clinicopathologic features have not been described.

To determine the expression status of DNA-PKcs in nonneoplastic gastric mucosa and gastric cancers, we evaluated its expression by immunohistochemistry in 122 non-neoplastic gastric mucosal tissues, and in 115 gastric adenoma and 564 consecutive gastric cancer specimens. In addition, we evaluated the clinicopathologic characteristics of gastric cancers with altered DNA-PKcs expression, and performed MSI analysis at BAT-26 and frameshift mutation analysis of DNA-PKcs.

\section{Materials and methods}

Gastric biopsy and gastric adenoma specimens. Gastric biopsy specimens from 122 patients who underwent routine gastroscopy at Seoul National University Bundang Hospital, Korea, were collected after obtaining given informed consent. None of the 122 patients concerned had gastric cancer or any other malignant neoplasm. These specimens were stained with hematoxylin and eosin (HE) and modified Giemsa. HE and Giemsa slides were reviewed according to the updated Sydney system and the presence of intestinal metaplasia was assessed (15). Gastric biopsy specimens were classified into three groups; 50 cases without Helicobacter pylori infection or inflammation, 42 cases with $H$. pylori-associated gastritis, and 30 cases with intestinal metaplasia. In addition, 115 surgically or endoscopically resected specimens of gastric adenoma were selected from the files of the Department of Pathology, Seoul National University College of Medicine.

Gastric cancer specimens. A total of 564 consecutive, surgically resected cases of gastric cancers (383 men and 181 women; 401 advanced and 163 early gastric cancers) treated over a period of one year were identified in the files of the Department of Pathology, Seoul National University College of Medicine. Age, sex, tumor location, lymphatic invasion, vascular invasion and pTNM stage (16) were evaluated by reviewing medical charts and pathologic records. Mean patient age was 55.0 years, and $92.2 \%$ of patients underwent curative resection (R0 according to the AJCC guideline). No patient had fulfilled the Amsterdam criteria for HNPCC (17). No patient had received preoperative chemo- or radiotherapy.

Tissue slides were reviewed for histologic classification (according to WHO and Lauren's classifications) (18) and neutrophil counting. Neutrophilic infiltration levels were scored as absent (absent or sparse), mild (rare and difficult to detect), moderate (formed aggregates and easily detected), and marked (neutrophil count exceeded tumor cell count). Clinical outcomes were followed from the date of surgery and the follow-up periods were 1-72 months (mean: 52 months). Data concerning cases lost to follow-up and deaths due causes other than gastric cancer were regarded as censored data for survival rate analysis.

This study was approved by the Institutional Review Boards for research using human subjects at Seoul National University College of Medicine and Seoul National University Bundang Hospital.

Tissue array method. Core tissue biopsies (2 $\mathrm{mm}$ in diameter) were taken from individual paraffin-embedded gastric biopsy specimens and gastric cancer specimens (donor blocks) and arranged in a new recipient paraffin block (tissue array block), as previously described (19). Each tissue array block contained up to 60 cases. As an excellent agreement exists between the staining results obtained from different intra-tumoral areas in gastric cancers, a core was sampled from each case (19). Adequate cases were those where a tumor occupied $>10 \%$ of the core area. Sections $(4 \mu \mathrm{m})$ were cut from each tissue array block, deparaffinized and dehydrated.

Immunohistochemistry. Immunohistochemical staining against DNA-PKcs (goat polyclonal antibody: Santa Cruz Biotechnology, Santa Cruz, CA) was performed using a streptavidin peroxidase procedure (labeled streptavidin-biotin) after microwave antigen retrieval. Immunolabeling level in each case was scored as strongly positive, moderately positive, faint, or negative, and immunolabeling pattern was scored as diffusely positive (50\%), focally positive (10-49\%), or negative $(<10 \%)$. For statistical analysis, immunostaining was considered positive, if $\geq 10 \%$ of the cells were strongly or moderately stained (20).

Microsatellite analysis. DNAs of cancerous tissue and corresponding normal gastric mucosal tissue were available in 515 of the 564 gastric cancer cases. The DNA extraction, PCR for BAT-26 and BAT-25, and DNA detection by DNA Sequencer (PRISM 377, Perkin-Elmer Corp., Foster City, CA) were performed as previously described (12). Because previous studies have shown that MSI at BAT-26 reflects the MSI-H phenotype, cancers with alteration at BAT-26 were categorized as having this phenotype $(12,21)$. In this study, no short BAT-26 allele was found in PCR products from corresponding normal DNA samples.

Frameshift mutation analysis. Repetitive mononucleotide tracts [the poly $(\mathrm{A})_{8}$ and poly $(\mathrm{A})_{10}$ tracts] of $D N A-P K c s$ were amplified in $37 \mathrm{MSI}-\mathrm{H}$ gastric cancers with available 
Table I. Expression status of DNA-PKcs in various lesions of gastric mucosal lesions.

\begin{tabular}{lccccc}
\hline & $\begin{array}{c}\text { Normal } \\
\text { (foveolar epithelium) } \\
(\%)\end{array}$ & $\begin{array}{c}\text { H. pylori-chronic } \\
\text { active gastritis } \\
(\%)\end{array}$ & $\begin{array}{c}\text { Intestinal } \\
\text { metaplasia } \\
(\%)\end{array}$ & $\begin{array}{c}\text { Tubular } \\
\text { adenoma } \\
(\%)\end{array}$ & $\begin{array}{c}\text { Gastric } \\
\text { cancer } \\
(\%)\end{array}$ \\
\hline $\begin{array}{l}\text { Negative expression } \\
\text { Positive expression }\end{array}$ & $50(100)$ & $0(0)$ & $0(0)$ & $2(1.7)$ & $114(20.2)$ \\
Total & $0(0)$ & $42(100)$ & $30(100)$ & $113(98.3)$ & $450(79.8)$ \\
\hline
\end{tabular}

$\mathrm{p}<0.001$ by $\chi^{2}$ test or linear-to-linear association.
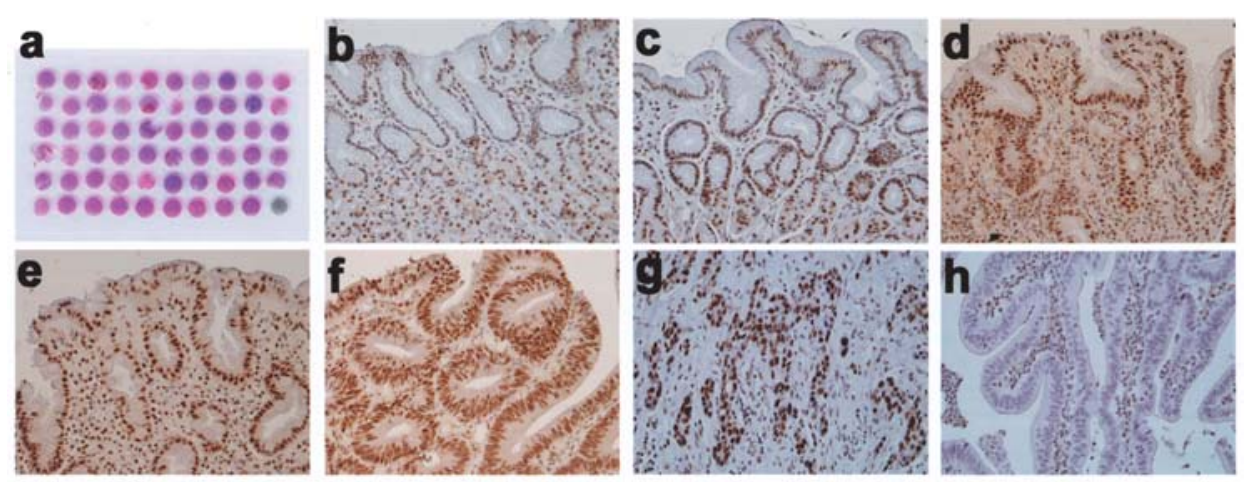

Figure 1. DNA-PKcs expression by immunohistochemistry in non-neoplastic gastric mucosa, gastric adenoma, and in gastric cancers. (a) Overview of tissue array slide (hematoxylin and eosin stain, x1). (b) Gastric body mucosa without $H$. pylori infection or inflammation (x400). (c) Gastric antral mucosa without H. pylori infection or inflammation (x400). (d) H. pylori-associated gastritis (x400). (e) Intestinal metaplasia (x400). (f) Gastric adenoma (x400). (g) DNAPKcs-positive gastric cancer (x400). (h) DNA-PKcs-negative gastric cancer (x400).

additional DNA after MSI analysis. These repetitive mononucleotide tracts of DNA-PKCS were also amplified in 26 MSS gastric cancers negative for DNA-PKcs expression. The PCR primer sets used were as follows: poly $(\mathrm{A})_{8}$ tract, 5'-TGGAGCAATGATGTAAGAGCTG-3' and 5'-AAAT AGCAGGCTGTGCCAGT-3'; and poly(A) $)_{10}$ tract, 5'-CTAT GGAGAACTTGCATTGA-3' and 5'-TTTTGTTTGGTTC CATTTTGG- $3^{\prime}$. The reaction involved 32 cycles at $95^{\circ} \mathrm{C}$ for $30 \mathrm{sec}, 59^{\circ} \mathrm{C}$ for $30 \mathrm{sec}$, and $65^{\circ} \mathrm{C}$ for $1 \mathrm{~min}$ for the poly $(\mathrm{A})_{8}$ tract and 35 cycles at $95^{\circ} \mathrm{C}$ for $30 \mathrm{sec}, 45^{\circ} \mathrm{C}$ for $30 \mathrm{sec}$, and $65^{\circ} \mathrm{C}$ for $1 \mathrm{~min}$ for the poly $(\mathrm{A})_{10}$ tract. Additional bands in the PCR products of tumor DNA, not observed in normal tissue, were interpreted as frameshift mutations.

Statistical analyses. The $\chi^{2}$ test or Fisher's exact test (twosided) was performed. Survival curves were plotted using the Kaplan-Meier product-limit method, and differences between the survival curves were tested using the log-rank test. Multivariate survival analysis was performed using the Cox proportional hazards model. Results were considered to be statistically significant when P-values were $<0.05$. All statistical analyses were conducted using the SPSS 12.0 statistical software program (SPSS, Chicago, IL).

\section{Results}

DNA-PKcs expression in gastric biopsy specimens, gastric adenoma, and gastric cancer. Table I details DNA-PKcs expression results in normal gastric mucosa, H. pyloriassociated gastritis, intestinal metaplasia, gastric adenoma and in gastric cancer. In the 50 normal gastric mucosa samples without $H$. pylori infection or inflammation, negative DNAPKcs expression was found in superficial foveolar epithelium, but positive expression was found in the neck zone and in the deep glands of body and antrum (Fig. $1 \mathrm{~b}$ and c). All 42 H. pylori-associated gastritis and 30 intestinal metaplasia samples showed positive expression of DNA-PKcs in both superficial epithelium and deep glands (Fig. 1d and e). Of the 115 cases of gastric adenoma samples, $113(98.3 \%)$ showed positive expression of DNA-PKcs (Fig. 1f). Of the 564 consecutive gastric cancers, 450 (79.8\%) showed positive expression of DNA-PKcs, and negative expression was found in the remaining 114 (20.2\%) samples (Fig. 1g and h).

DNA-PKcs expression status and clinicopathologic features in gastric cancer. Table II demonstrates the correlations between clinicopathologic parameters and DNA-PKcs expression. Regarding tumor progression, gastric cancers negative for DNA-PKcs were more likely to be advanced than early cancers $(\mathrm{p}<0.001)$, and to have a higher pTNM stage $(\mathrm{p}=0.002)$. Cases negative for DNA-PKcs expression also showed more frequent lymphatic invasion $(\mathrm{p}=0.005)$ and lymph node metastasis $(\mathrm{p}=0.001)$ than positive cases.

Our histologic review of gastric cancer samples showed neutrophil infiltration in intratumoral stroma. Of the 564 gastric cancer samples, neutrophilic infiltration was mild in 54 cases $(9.7 \%)$, moderate in 44 cases $(7.9 \%)$, and marked in 
Table II. Correlation between DNA-PKcs expression and clinicopathologic parameters in consecutive gastric carcinomas.

\begin{tabular}{|c|c|c|c|c|}
\hline \multirow[t]{2}{*}{ Characteristics } & \multirow[t]{2}{*}{ Total } & \multicolumn{2}{|c|}{ DNA-PKcs expression } & \multirow[t]{2}{*}{ P-value } \\
\hline & & $\begin{array}{c}\text { Negative } \\
(\%)\end{array}$ & $\begin{array}{c}\text { Positive } \\
(\%)\end{array}$ & \\
\hline Age (mean) & 564 & $57.1 \pm 11.3$ & $54.5 \pm 12.8$ & $0.011^{\mathrm{a}}$ \\
\hline Gender & & & & 0.751 \\
\hline Male & 383 & $76(19.8)$ & $307(80.2)$ & \\
\hline Female & 181 & $38(21.0)$ & $143(79.0)$ & \\
\hline Location & & & & 0.273 \\
\hline Low & 262 & $60(22.9)$ & $202(77.1)$ & \\
\hline Middle & 240 & $41(17.1)$ & $199(82.9)$ & \\
\hline Upper & 15 & $6(40.0)$ & $9(60.0)$ & \\
\hline Whole & 47 & $7(14.9)$ & $40(85.1)$ & \\
\hline Tumor size (cm) & 564 & $6.1 \pm 2.7$ & $5.2 \pm 3.1$ & 0.177 \\
\hline WHO classification & & & & $0.002^{\mathrm{a}}$ \\
\hline WD and MD & 219 & $50(22.8)$ & $169(77.2)$ & \\
\hline $\mathrm{PD}$ & 241 & $57(23.7)$ & $184(76.3)$ & \\
\hline Mucinous & 32 & $2(6.3)$ & $30(93.7)$ & \\
\hline SRC & 72 & $5(6.9)$ & $67(93.1)$ & \\
\hline Lauren classification & & & & 0.124 \\
\hline Intestinal & 217 & $51(23.5)$ & $166(76.5)$ & \\
\hline Diffuse & 347 & $63(18.2)$ & $284(81.8)$ & \\
\hline Depth of invasion & & & & $<0.001^{\mathrm{a}}$ \\
\hline Advanced & 401 & $106(26.4)$ & $295(73.6)$ & \\
\hline Early & 163 & $8(4.9)$ & $155(95.1)$ & \\
\hline Lymph node metastasis & & & & $0.001^{\mathrm{a}}$ \\
\hline Absent & 207 & $26(12.6)$ & $181(87.4)$ & \\
\hline Present & 357 & 88 (24.6) & $269(75.4)$ & \\
\hline Distant metastasis & & & & 0.880 \\
\hline Absen & 523 & $106(20.3)$ & $417(79.7)$ & \\
\hline Present & 41 & $8(19.5)$ & $33(80.5)$ & \\
\hline Stage & & & & $0.002^{\mathrm{a}}$ \\
\hline I & 225 & $26(11.6)$ & $199(88.4)$ & \\
\hline II & 125 & $34(27.2)$ & $91(72.8)$ & \\
\hline III & 124 & $33(26.6)$ & $91(73.4)$ & \\
\hline IV & 90 & $21(23.3)$ & $69(76.7)$ & \\
\hline Lymphatic invasion & & & & $0.005^{\mathrm{a}}$ \\
\hline Absent & 393 & $67(17.1)$ & $326(82.9)$ & \\
\hline Present & 171 & $47(27.5)$ & $124(72.5)$ & \\
\hline Neutrophilic stroma & & & & $<0.001^{\circ}$ \\
\hline Absent & 491 & $86(17.5)$ & $405(82.5)$ & \\
\hline Present & 73 & $28(38.4)$ & 45 (61.6) & \\
\hline MSI & & & & $<0.001$ \\
\hline Negative & 455 & 77 (16.9) & $378(83.1)$ & \\
\hline Positive & 60 & $23(38.3)$ & 37 (61.7) & \\
\hline Total & 564 & $114(20.2)$ & $450(79.8)$ & \\
\hline
\end{tabular}

${ }^{\mathrm{a}} \mathrm{p}<0.05$. 


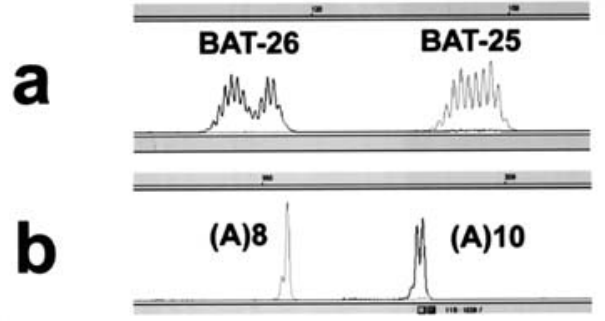

Figure 2. Microsatellite instability and frameshift mutation of DNA-PKcs. (a) Analysis of BAT-26 and BAT-25 alleles. (b) Frameshift mutations of the (A) $)_{10}$ repeat of DNA-PKcs.

36 cases $(6.5 \%)$. The moderate and marked groups were classified as gastric cancer with neutrophilic stroma. Interestingly, gastric cancers negative for DNA-PKcs frequently had intratumoral neutrophilic stroma $(\mathrm{p}<0.001)$ (Table II).
Microsatellite instability and DNA-PKcs. Of 515 gastric cancer specimens tested, 60 (11.7\%) had the MSI-H phenotype, and DNA-PKcs negativity was significantly higher in MSI-H than in MSS gastric cancers $(\mathrm{p}<0.001)$ (Table II, Fig. 2a).

In terms of the relationship between the presence of frameshift mutation and clinicopathologic features in gastric cancer, we performed frameshift mutation analysis at poly $(\mathrm{A})_{8}$ and poly $(\mathrm{A})_{10}$ tracts of DNA-PKcs in $37 \mathrm{MSI}-\mathrm{H}$ cancers and 26 MSS cancers (Fig. 2b). No frameshift mutation of poly $(\mathrm{A})_{8}$ was found in any of these cancers. However, 9 of the 37 MSI-H gastric cancers $(24.3 \%)$ but none of the 26 MSS cancers had frameshift mutations of poly $(\mathrm{A})_{10}$ tract $(\mathrm{p}=0.008)$ (Table III). The presence of a frameshift mutation of the poly $(\mathrm{A})_{10}$ tract was significantly correlated with DNAPKcs expression ( $\mathrm{p}=0.017$ ) (Table IV).

Patients with MSI-H gastric cancer were more likely to have less lymph node metastasis $(\mathrm{p}=0.005)$ (Table V).

Table III. Correlation between $(\mathrm{A})_{10}$ frameshift mutations of DNA-PKcs and MSI in gastric carcinomas.

\begin{tabular}{lccc}
\hline Microsatellite instability & Total & & \multicolumn{2}{l}{ Frameshift mutation of DNA-PKcs } & Absent $(\%)$ \\
\cline { 3 - 4 } & & Present $(\%)$ & $26(100)$ \\
Microsatellite stable (MSS) & 26 & $0(0)$ & $28(75.7)$ \\
\hline
\end{tabular}

Table IV. Correlation between $\mathrm{A}_{(10)}$ frameshift mutations and the expression status of DNA-PKcs in MSI-H gastric carcinomas.

\begin{tabular}{lrcc}
\hline $\begin{array}{l}\text { Frameshift mutation analysis } \\
\text { in MSI-H gastric carcinomas }\end{array}$ & Total & \multicolumn{2}{c}{ DNA-PKcs expression } \\
& & Negative (\%) & Positive (\%) \\
\hline Frameshift mutation: Absent & 28 & $8(28.6)$ & $20(71.4)$ \\
Frameshift mutation: Present & 9 & $7(77.8)$ & $2(22.2)$ \\
Total & 37 & 15 & 22 \\
\hline
\end{tabular}

Table V. Correlation between lymph node metastasis and MSI or DNA-PKcs frameshift mutations in gastric carcinomas.

\begin{tabular}{lrrr}
\hline & Total & \multicolumn{2}{c}{ Lymph node metastasis } \\
\cline { 3 - 3 } & & Absent $(\%)$ & Present $(\%)$ \\
\hline Microsatellite instability & & & \\
$\quad$ MSS & 455 & $32(53.3)$ & $297(65.3)$ \\
MSI-H & 60 & & $28(46.7)$ \\
Frameshift mutation & & $17(60.7)$ & $11(39.3)$ \\
$\quad$ Negative & 28 & $2(22.2)$ & $7(77.8)$ \\
$\quad$ Positive & 9 & & 0.044 \\
\hline
\end{tabular}




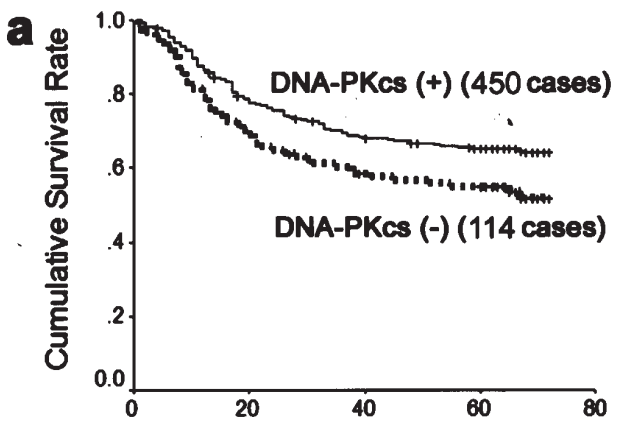

Follow-up Months after Surgery

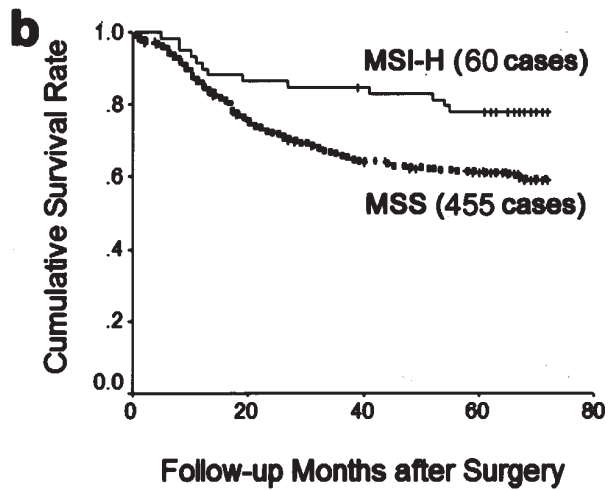

Figure 3. Kaplan-Meier survival curves for gastric cancer patients. (a) DNA-PKcs expression was significantly associated with patient survival $(\mathrm{p}=0.0135)$. (b) The MSI-H phenotype was significantly associated with patient survival $(\mathrm{p}=0.0112)$.

Among the MSI-H gastric cancers, a subgroup with (A) $)_{10}$ mutation was found to be more likely to have metastasis to lymph nodes, with statistical significance $(\mathrm{p}=0.044)$.

Survival analysis. Univariate survival analysis by KaplanMeier survival curves showed that patients negative for DNA-PKcs expression had significantly poorer survival than those positive for DNA-PKcs expression $(\mathrm{p}=0.0135)$ (Fig. 3a). The 5-year survival rate was $65.3 \pm 2.3 \%$ in patients positive for DNA-PKcs, and $54.7 \pm 4.7 \%$ in patients negative for DNA-PKcs. Univariate survival analysis also showed that patients with MSS gastric cancer had significantly poorer survival than those with MSI-H gastric cancer $(\mathrm{p}=0.0112)$ (Fig. 3b). By multivariate analysis including pTNM stage, MSI, and DNA-PKcs expression, only pTNM was identified as an independent prognostic indicator $(\mathrm{p}<0.001)$.

\section{Discussion}

Cells are continually assaulted by a plethora of DNA damaging agents, and unrepaired or incorrectly repaired DNA damage can result in gene mutations and consequently alter proteins that control cell growth or survival (22). Since DNA damage can arise in many different ways, various DNA repair systems have evolved to protect cells from specific types of DNA damage. The DNA DSB repair apparatus is specific for DNA DSBs, which are the major lesions induced by ionizing radiation (23), and DNA-PKcs participates in DNA DSB repair and thus, the maintenance of genomic integrity. In fact, DNA-PKcs downregulation has been reported in several human cancers $(24,25)$. On the other hand, it has been reported by a numbers of studies that the DNA$P K c s$ gene is rarely mutated in human cancer and that DNAPKcs is frequently overexpressed $(5,8,26)$. Our aim in this study was to determine the expression status and clinical implications of DNA-PKcs in gastric carcinogenesis and cancer progression.

In this study, DNA-PKcs was found to be localized in cell nuclei of various tissue samples. In foveolar epithelium of normal gastric mucosa, negative expression of DNA-PKcs was observed. DNA-PKcs expression was found to be increased in $H$. pylori-associated gastritis, intestinal metaplasia, and gastric adenoma vs. normal gastric mucosa. $H$. pylori is a gram-negative bacterium and was classified as a type I carcinogen by the WHO in 1994. H. pylori has been reported to trigger hyperproliferation and to take direct command of epithelial cell signaling, including the activation of tyrosine kinase receptors $(27,28)$. Increased expression of DNA-PKcs in H. pylori-associated gastritis may be associated with epithelial hyperproliferation or transcriptional changes. In addition to $H$. pylori infection, hyperproliferative processes or transcriptional changes has also been reported in intestinal metaplasia and gastric adenoma (29).

In contrast to premalignant lesions of the stomach, i.e., H. pylori-associated gastritis, intestinal metaplasia or gasrtic adenoma, negative DNA-PKcs expression was observed in 114 of 564 consecutive gastric cancers (20.2\%). The present study demonstrates that gastric cancers negative for DNA-PKcs are associated with an advanced stage, a high prevalence of lymph node metastasis, and poor patient survival. Several functions of DNA-PKcs have been suggested to be associated with tumor progression and patient survival. For example, DNA DSBs not repaired due to functional loss of DNA-PKcs would result in the generation of acentric chromosome fragments during mitosis (22). The presence of such unstable chromosomes during cell proliferation may be associated with tumor progression, invasion and metastasis.

Negative DNA-PKcs expression in gastric cancer may also have clinical significance. DNA-PKcs is a component of the DNA DSB repair apparatus, and has been suggested to be a candidate for cancer therapy because reduced DNAPKcs levels have been associated with an increased sensitivity to ionizing radiation $(4,5,30)$. Recently, adjuvant and neoadjuvant chemoradiation therapies were found to have a benefit in gastric cancer treatments $(31,32)$. Therefore, the expression status of DNA-PKcs might be a molecular marker of response to radiation therapy in gastric cancer.

MSI is a form of genomic instability associated with defective DNA mismatch repair in tumors. Frameshift mutations at coding mononucleotide repeat sequences are common in MSI-H tumors, and higher mutational rates are related to the lengths of mononucleotide repeat sequences in target genes (9). DNA-PKCs gene has two coding mononucleotide repeats, i.e., poly $(\mathrm{A})_{8}$ and $\operatorname{poly}(\mathrm{A})_{10}$, and frameshift mutations of the poly $(\mathrm{A})_{10}$ tract of DNA-PKcs has been reported $(13,14)$. In this study, frameshift mutations of the poly $(\mathrm{A})_{10}$ tract of DNA-PKcs was found in $24.3 \%$ of MSI-H gastric cancers, but no frameshift mutations in poly $(\mathrm{A})_{8}$ tract was found in MSI-H or MSS gastric cancers. Frameshift 
mutation of the $(\mathrm{A})_{10}$ tract of DNA-PKcs was found to be significantly associated with the expression status of DNAPKcs. These findings suggests that frameshift mutation of the poly $(\mathrm{A})_{10}$ tract of DNA-PKCs is a target in MSI-H gastric cancers and that frameshift mutation is an expressional loss mechanism.

MSI-H colorectal and gastric cancers show lower levels of lymph node metastasis and better survival rates than MSS cancers $(11,12)$. Of frameshift mutations of various target genes, TGFßRII mutations have been suggested to be associated with improved survival. TGFß1 is a potent growth inhibitor, with tumor-suppressing activity. Recently, a number of studies have shown that TGFß1 has tumor-suppressing activity, and that it can also drive malignant progression, invasion and metastasis both in vitro and in vivo (33). Therefore, it appears that complete abrogation of TGF 3 signaling due to TGF $\beta R I I$ mutations, although leading to loss of growth control and early tumor onset, paradoxically has a protective effect on tumor progression. However, MSI-H gastric cancers with the (A) ${ }_{10}$ mutation in DNA-PKcs were found to be more likely to be associated with lymph node metastasis than cancers without mutation. These finding suggest that target gene mutations are important determinators of clinical outcome in MSI-H cancer patients.

Tumors do not exclusively consist of neoplastic cells, but they also contain stromal compartments composed of a variety of non-malignant cells. It has become increasingly clear that the tumor environment plays an important role in malignant disease $(34,35)$. In some experiments, intratumoral neutrophils were found to cause tumor cell cytolysis and to have potential to eliminate the tumor cell population (36), whereas in others, neutrophils were found to contribute to invasive potential (37). In gastric cancers, the roles of neutrophils in carcinogenesis and cancer progression were not known, and clinical or molecular characteristics of gastric cancers with neutrophilic stroma have not been established. In this study, negative expression of DNA-PKcs was more frequently found in gastric cancers with moderate or marked neutrophilic infiltration, suggesting the correlation between DNA-PKcs expression and intratumoral neutrophilic infiltration.

In summary, negative expression of DNA-PKcs was found in normal gastric mucosa, but positive expression was found in premalignant lesions of stomach. In gastric cancers, DNA-PKcs expression was not observed in 114 of $564(20.2 \%)$ cases, and negative expression was significantly associated with the presence of intratumoral neutrophils, the MSI-H phenotype, tumor progression, and poor survival. Frameshift mutations of the $(\mathrm{A})_{10}$ mononucleotide repeat of DNA-PKCs were found in $24.3 \%$ of MSI-H gastric cancers and were associated with negative DNA-PKcs expression. Although the patients with MSI-H gastric cancers were more likely to have lower risk of lymph node metastasis, gastric cancers with the $(\mathrm{A})_{10}$ mutation of DNA-PKcs were associated with metastasis to lymph nodes.

\section{Acknowledgements}

We thank S.P. Kim, S.I. Choi, and Superbiochip Laboratories (Seoul, Korea) for their technical assistance. This work was supported by FG06-11-03 of 21C Frontier Functional Human Genome Project From Ministry of Science and Technology of Korea.

\section{References}

1. Ramsden DA and Gellert $\mathrm{M}$ : $\mathrm{Ku}$ protein stimulates DNA end joining by mammalian DNA ligases: a direct role for $\mathrm{Ku}$ in repair of DNA double-strand breaks. EMBO J 17: 609-614, 1998.

2. Chan DW and Lees-Miller SP: The DNA-dependent protein kinase is inactivated by autophosphorylation of the catalytic subunit. J Biol Chem 271: 8936-8941, 1996.

3. Suwa A, Hirakata M, Takeda Y, Jesch SA, Mimori T and Hardin JA: DNA-dependent protein kinase (Ku protein-p350 complex) assembles on double-stranded DNA. Proc Natl Acad Sci USA 91: 6904-6908, 1994.

4. Daido S, Yamamoto A, Fujiwara K, Sawaya R, Kondo S and Kondo Y: Inhibition of the DNA-dependent protein kinase catalytic subunit radiosensitizes malignant glioma cells by inducing autophagy. Cancer Res 65: 4368-4375, 2005.

5. Shintani S, Mihara M, Li C, Nakahara Y, Hino S, Nakashiro K and Hamakawa $\mathrm{H}$ : Up-regulation of DNA-dependent protein kinase correlates with radiation resistance in oral squamous cell carcinoma. Cancer Sci 94: 894-900, 2003

6. Kurimasa A, Ouyang H, Dong LJ, et al: Catalytic subunit of DNA-dependent protein kinase: impact on lymphocyte development and tumorigenesis. Proc Natl Acad Sci USA 96: 1403-1408, 1999.

7. Rigas B, Borgo S, Elhosseiny A, et al: Decreased expression of DNA-dependent protein kinase, a DNA repair protein, during human colon carcinogenesis. Cancer Res 61: 8381-8384, 2001.

8. Hosoi Y, Watanabe T, Nakagawa K, et al: Up-regulation of DNA-dependent protein kinase activity and $\mathrm{Sp} 1$ in colorectal cancer. Int J Oncol 25: 461-468, 2004.

9. Boland CR, Thibodeau SN, Hamilton SR, et al: A national cancer institute workshop on microsatellite instability for cancer detection and familial predisposition: development of international criteria for the determination of microsatellite instability in colorectal cancer. Cancer Res 58: 5248-5257, 1998.

10. Aaltonen L, Peltomaki P, Leach FS, et al: Clues to the pathogenesis of familial colorectal cancer. Science 260: 812-816, 1993.

11. Gryfe R, Kim H, Hsieh ETK, et al: Tumor microsatellite instability and clinical outcome in young patients with colorectal cancer. N Engl J Med 342: 69-77, 2000.

12. Lee HS, Choi SI, Lee HK, et al: Distinct clinical features and outcomes of gastric cancers with microsatellite instability. Mod Pathol 15: 632-640, 2002

13. Mongiat-Artus P, Miquel C, van der Aa M, et al: Microsatellite instability and mutation analysis of candidate genes in urothelial cell carcinomas of upper urinary tract. Oncogene 25: 2113-2118, 2006.

14. Li HR, Shagisultanova EI, Yamashita K, Piao Z, Perucho M and Malkhosyan SR: Hypersensitivity of tumor cell lines with microsatellite instability to DNA double strand break producing chemotherapeutic agent bleomycin. Cancer Res 64: 4760-4767, 2004.

15. Dixon MF, Genta RM, Yardley JH and Correa P: Classification and grading of gastritis. The updated Sydney System. International Workshop on the Histopathology of Gastritis, Houston 1994. Am J Surg Pathol 20: 1161-1181, 1996.

16. American Joint Committee on Cancer: AJCC Cancer Staging Manual. 6th edition. Springer-Verlag, New York, 2002.

17. Vasen HF, Mecklin JP, Khan PM and Lynch HT: The international collaborative group on hereditary non-polyposis colorectal cancer (ICG-HNPCC). Dis Colon Rectum 34: 424-425, 1991.

18. International Agency for Research on Cancer (IARC): World Health Organization Classification of Tumors; Pathology and Genetics of Tumors of the Digestive System. IARC Press, Lyon, 2000.

19. Lee HS, Lee HK, Kim HS, Yang HK, Kim YI and Kim WH: MUC1, MUC2, MUC5AC, and MUC6 expressions in gastric carcinomas: their roles as prognostic indicators. Cancer 92: 1427-1434, 2001.

20. Lee HS, Lee HK, Kim HS, Yang HK and Kim WH: Tumor suppressor gene expression correlates with gastric cancer prognosis. J Pathol 200: 39-46, 2003. 
21. Hoang JM, Cottu PH, Thuille B, Salmon RJ, Thomas G and Hamelin R: BAT-26, an indicator of the replication error phenotype in colorectal cancers and cell lines. Cancer Res 57: 300-303, 1997.

22. Lindahl T: Genetic instability in cancer. In: DNA Damage Detection by DNA Dependent Protein Kinase and Related Enzymes. Jackson SP (ed). Cold Spring Harbor Laboratory Press, New York, pp261-279, 1996.

23. Dynan WS and Yoo S: Interaction of Ku protein and DNAdependent protein kinase catalytic subunit with nucleic acids. Nucleic Acids Res 26: 1551-1559, 1998.

24. Moll U, Lau R, Sypes MA, Gupta MM and Anderson CW: DNA-PK, the DNA-activated protein kinase, is differentially expressed in normal and malignant human tissues. Oncogene 18: 3114-3126, 1999.

25. Sakata K, Matsumoto Y, Tauchi H, et al: Expression of genes involved in repair of DNA double-strand breaks in normal and tumor tissues. Int J Radiat Oncol Biol Phys 49: 161-167, 2001.

26. Um JH, Kwon JK, Kang CD, et al: Relationship between antiapoptotic molecules and metastatic potency and the involvement of DNA-dependent protein kinase in the chemosensitization of metastatic human cancer cells by epidermal growth factor receptor blockade. J Pharmacol Exp Ther 311: 1062-1070, 2004.

27. De Freitas D, Urbano M, Goulao MH, et al: The effect of Helicobacter pylori infection on apoptosis and cell proliferation in gastric epithelium. Hepatogastroenterology 51: 876-882, 2004.

28. Naumann M and Crabtree JE: Helicobacter pylori-induced epithelial cell signalling in gastric carcinogenesis. Trends Microbiol 12: 29-36, 2004.

29. Shiotani A, Iishi H, Ishiguro S, Tatsuta M, Nakae Y and Merchant JL: Epithelial cell turnover in relation to ongoing damage of the gastric mucosa in patients with early gastric cancer: increase of cell proliferation in paramalignant lesions. J Gastroenterol 40: 337-344, 2005.
30. An J, Xu QZ, Sui JL, Bai B and Zhou PK: Downregulation of c-myc protein by siRNA-mediated silencing of DNA-PKcs in HeLa cells. Int J Cancer 117: 531-537, 2005.

31. Kim S, Lim DH, Lee J, et al: An observational study suggesting clinical benefit for adjuvant postoperative chemoradiation in a population of over 500 cases after gastric resection with D2 nodal dissection for adenocarcinoma of the stomach. Int $\mathbf{J}$ Radiat Oncol Biol Phys 63: 1279-1285, 2005.

32. Van Cutsem E, Dicato M, Arber N, et al: The neo-adjuvant, surgical and adjuvant treatment of gastric adenocarcinoma. Current expert opinion derived from the Seventh World Congress on Gastrointestinal Cancer, Barcelona, 2005. Ann Oncol 17 (Suppl 6): vi13-18, 2006.

33. Oft M, Heider $\mathrm{KH}$ and Beug $\mathrm{H}$ : TGFbeta signaling is necessary for carcinoma cell invasiveness and metastasis. Curr Biol 8: 1243-1252, 1998.

34. Coussens LM and Werb Z: Inflammation and cancer. Nature 420: 860-867, 2002.

35. Oosterling SJ, van der Bij GJ, Meijer GA, et al: Macrophages direct tumour histology and clinical outcome in a colon cancer model. J Pathol 207: 147-155, 2005.

36. Di Carlo E, Forni G, Lollini P, Colombo MP, Modesti A and Musiani P: The intriguing role of polymorphonuclear neutrophils in antitumor reactions. Blood 97: 339-345, 2001.

37. Imai $Y$, Kubota $Y$, Yamamoto S, et al: Neutrophils enhance invasion activity of human cholangiocellular carcinoma and hepatocellular carcinoma cells: an in vitro study. J Gastroenterol Hepatol 20: 287-293, 2005. 